\title{
Omega-3 PUFA supplementation differentially affects behavior and cognition in the young and aged non-human primate Grey mouse lemur (Microcebus murinus)
}

\author{
Fabien Pifferi ${ }^{\star}$ \\ UMR 7179 Centre National de la Recherche Scientifique, Muséum National d'Histoire Naturelle, 1 avenue du Petit Château, \\ 91800 Brunoy, France
}

Received 1st November 2013 - Accepted 29 November 2013

\begin{abstract}
Data are divergent about the ability of dietary $\omega 3$ fatty acids to prevent age-associated cognitive decline. Most of the clinical trials failed to demonstrate a protective effect of $\omega 3$ fatty acids against cognitive decline and methodological issues are still under debate. Conversely to human studies, experiments performed in adult rodents clearly indicate that long chain $\omega 3$ fatty acids play a beneficial role in behavioral and cognitive functions. Inconsistent observations between human and rodent studies highlight the importance of the use of non-human primate models. We recently started a series of experiments on Grey mouse lemurs, an emerging non-human primate model of aging in order to assess the impact of $\omega 3$ fatty acids dietary supplementation on several brain functions. These experiments started with the determination of the fatty acids composition of target organs (brain, adipose tissue, liver, plasma) of animals fed under control diet. We then explored the impact of $\omega 3$ polyunsaturated fatty acids (PUFA) supplementation on cognition and behavior in young and aged grey mouse lemurs. The aim of the present review is to compare the observations made in young and aged grey mouse lemurs and to explore the possibilities of new experiments in order to bridge the gap between rodents and Humans.
\end{abstract}

Keywords: Grey mouse lemur / non-human primate / PUFA / aging / cognition / behavior

Résumé - Les acides gras omega-3 affectent différemment le comportement et la cognition chez un primate nonhumain jeune ou âgé, le Microcèbe (Microcebus murinus). Les données divergent quant à la capacité des acides gras $\omega 3$ à prévenir le déclin cognitif associé à l'âge. La plupart des essais cliniques réalisés jusqu'à présent ne permettent pas de démontrer d'effet protecteur des $\omega 3$ contre le déclin cognitif, des problèmes méthodologiques étant encore débattus. Contrairement aux études cliniques, des expériences réalisées chez le rongeur adulte indiquent clairement que les $\omega 3$ à longue chaîne ont un rôle bénéfique sur les fonctions comportementales et cognitives, y compris au cours du vieillissement. Les observations contradictoires entre les études humaines et celles réalisées chez le rongeur soulignent l'importance de l'utilisation de primates non-humains. Nous avons récemment commencé une série d'expériences chez un primate non-humain, le Microcèbe (Microcebus murinus), un modèle émergent du vieillissement, afin d'évaluer l'impact d'une supplémentation alimentaire en $\omega 3$ sur les fonctions cérébrales. Ces expériences ont commencé avec la détermination de la composition en acides gras de certains organes cibles (cerveau, tissu adipeux, foie, plasma) d'animaux nourris sous régime standard. Nous avons ensuite exploré l'impact des $\omega 3$ sur la cognition et le comportement chez de jeunes adultes, puis chez des individus âgés. L'objectif de la présente étude est de comparer les observations faites chez les lémuriens jeunes et âgés et d'explorer les possibilités de nouvelles expériences afin de combler le fossé expérimental entre rongeurs et humains.

Mots clés : Microcèbe / primate non-humain / AGPI / vieillissement / cognition / comportement

\section{Introduction}

In the brain, $\omega 3$ polyunsaturated fatty acids ( $\omega 3$ PUFA) are present in high quantities (up to $50 \%$ of total fatty acids in the cellular membranes of neurons and retina). One longchain derivative of the $\omega 3$ family is present in very high quantities in the brain: docosahexaenoic acid (DHA). In animals,

\footnotetext{
^ Correspondence: pifferi@mnhn.fr
}

a decrease in membrane DHA, obtained by dietary deficiency, is accompanied by severe neurosensory disturbances (learning, behavior, vision) (Lavialle et al., 2007). DHA is known to be involved in modulating the activity and expression of membrane proteins such as receptors, transporters, pumps and ion channels at several stages of neurotransmission (Guesnet et al., 2005). The importance of $\omega 3$ fatty acids for the aging brain is revealed by epidemiological studies that address the question of a protective effect of fish and DHA against the risk 
of Alzheimer's disease, a question that remains under debate (reviewed in Bégin et al., 2009, 2010; Barberger-Gateau et al., 2013).

In addition, in both animals and Humans, a low dietary level of DHA has been associated with increased risk of developing neuropsychiatric diseases. Even if large clinical trials are lacking in Humans, a reduced abundance of $\omega 3$ PUFA have been reported in patients with anxiety, while supplementation with $\omega 3$ PUFA appears to inhibit activation of the hypothalamic-pituitary-adrenal axis and can ameliorate some of the symptoms of anxiety (Ross, 2009). In animals, Larrieu et al. (2012) recently demonstrated that long-term exposure to an $\omega 3$ deficient diet decreases the level of DHA in the brain and impairs the cannabinoid receptor signaling pathway in moodcontrolling structures. Mathieu et al. (2011) also evidenced such a link, supporting the notion that PUFA-unbalanced diet, together with early maternal stress, may be a determinant risk factor in emotional disorders.

Conversely to anxiety and mood disorders, data in rodents and Humans are divergent about the ability of dietary $\omega 3$ fatty acids to prevent age-associated cognitive decline. Indeed, most of the clinical trials failed to demonstrate a protective effect of $\omega 3$ fatty acids dietary supplements against cognitive decline and methodological issues are still under debate (Bégin et al., 2009, 2010). While $\omega 3$ supplementation studies in rodents demonstrated a general enhancement of cognitive functions (Fedorova and Salem, 2006), studies in humans are more controversial and have so far not shown clear beneficial effects (Bégin et al., 2009, 2010). However, these studies in rodent and Humans used very different experimental approaches and are therefore difficult to compare.

Inconsistent observations between human and rodent studies (in both adult and aged subjects) highlight the importance of the use of non-human primate models. To our knowledge, only one study investigated the impact of $\omega 3$ fatty acid supplementation on behavioral and cognitive functions in non-human primate species (Tsukada et al., 2000). In this study aged monkeys were supplemented with DHA for 1 to 4 weeks (a very short term dietary supplementation), leading to increased regional cerebral blood flow, a parameter closely linked to neuronal activation.

Non-human primates are at the crossroad between genetic models (such as Drosophila melanogaster and inbred mouse strains), non-transgenic rodent models, and human beings, and constitute indispensable models for physiological and biochemical research on ageing. For ageing research, non-human primate models are more relevant to human ageing than classical biological models, such as rodents (Lavery, 2000), for two reasons: (i) they share several genetic, physiological, and anatomical similarities (a complex nervous system in particular) with humans, (ii) they mimic the heterogeneity observed in the human population. Moreover, they can be studied under controlled experimental conditions more easily than humans.

The grey mouse lemur (Fig. 1) is a nocturnal prosimian primate originating from Madagascar. This non-human primate has a life expectancy of around 8 years (Languille et al., $2012 b$ ) and presents specific characteristics, e.g. omnivorous dietary habits and small size and weight (80 to $120 \mathrm{~g}$ ). Grey mouse lemur displays a common pattern of cognitive alteration

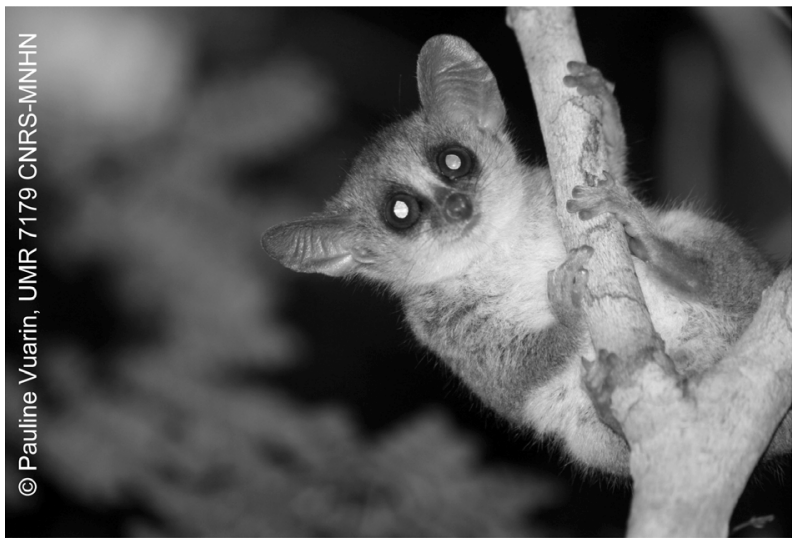

Fig. 1. The Grey mouse lemur (Microcebus murinus).

during ageing with human that make it a good model to evaluate the effects of dietary treatments on behavioral outcomes, especially in relation to aging or during dietary interventions (Dal-Pan et al., 2011; Picq et al., 2012). Specific tasks have been developed and adapted in our laboratory (Languille et al., 2012b; Picq et al., 2007) offering the possibility to evaluate in this small primate the impact of dietary supplements on longevity or cognitive functions. This nocturnal primate exhibits biological seasonal rhythms that are photoperiodically driven characterized in particular by a winter body mass gain and decreased resting metabolic rate (Perret and Aujard, 2001). The grey mouse lemur constitutes one of the rare non-transgenic primate models of spontaneous development of Alzheimer's disease, making this species an adequate model to test the possibility of a cognitive improvement after $\omega 3$ fatty acids supplementation in non-human primates (Languille et al., 2012). The grey mouse lemur could thus help bridge the gap between rodents and human studies.

In the present study we review our previously published experiments performed in young (Pifferi et al., 2012; Vinot et al., 2011) and aged (Languille et al., 2012b) grey mouse lemurs receiving or not a long-term dietary supplement of $\omega 3$ fatty acids (under the form of fish oil, naturally rich in longchain $\omega 3$ fatty acids). In these studies, we evaluated the impact of $\omega 3$ fatty acids on behavior and cognition in both adult and aged primates. We postulated that fish oil supplementation may improve behavioral and cognitive parameters which could be of major importance in the perspective of their use as supplemental ingredient in human foods. After a brief description of the fatty acid composition in lipid classes from the main target tissues (brain, retina, liver and adipose tissue) of non-supplemented animals, we will report the impact of fish oil supplementation on plasma total lipids fatty acids composition. The impact of fish oil supplementation on anxiety, measured in an open-field task, and spatial memory, measured in a radial arm maze task, will then be reported and discussed for both young and aged animals.

\section{Fatty acid composition of the main target tissues in non-supplemented animals}

In a first study (Pifferi et al., 2012), we reported the fatty acid composition in lipid classes from the main target tissues 
Table 1. Fatty acid composition $(\mathrm{g} / 100 \mathrm{~g})$ in plasma phospholipids of young and aged control (CTL) and fish oil (FO) supplemented animals.

\begin{tabular}{ccccc}
\hline & Young CTL $(n=6)$ & Young FO $(n=6)$ & Aged CTL $(n=6)$ & Aged FO $(n=6)$ \\
\hline Fatty acids $^{2}$ & \multicolumn{4}{c}{$\mathrm{g} / 100 \mathrm{~g}^{1}$} \\
\hline $16: 0$ & $24.8 \pm 0.6$ & $27.2 \pm 0.3^{*}$ & $17.2 \pm 0.6$ & $19.5 \pm 0.3$ \\
$18: 0$ & $16.7 \pm 0.8$ & $14.4 \pm 0.2^{*}$ & $12.0 \pm 0.2$ & $11.3 \pm 0.5$ \\
$\Sigma$ Saturated & $43.3 \pm 0.0$ & $45.0 \pm 0.6$ & $30.4 \pm 0.2$ & $32.0 \pm 1.0$ \\
$18: 1 \mathrm{n}-9$ & $9.0 \pm 0.0$ & $6.0 \pm 0.2^{*}$ & $14.2 \pm 1.7$ & $10.9 \pm 0.3$ \\
$18: 1 \mathrm{n}-7$ & $1.8 \pm 0.0$ & $1.3 \pm 0.0$ & $1.7 \pm 0.2$ & $0.6 \pm 0.4^{*}$ \\
$\Sigma$ MUFA & $11.6 \pm 0.0$ & $8.0 \pm 0.3^{*}$ & $18.0 \pm 1.7$ & $12.9 \pm 0.8^{*}$ \\
$18: 2 \omega 6$ & $13.4 \pm 1.4$ & $8.9 \pm 0.7^{*}$ & $16.9 \pm 0.8$ & $12.9 \pm 0.9^{*}$ \\
$20: 4 \omega 6^{\mathrm{a}}$ & $16.3 \pm 0.1$ & $9.6 \pm 1.2^{*}$ & $24.5 \pm 1.5$ & $16.2 \pm 2.6^{*}$ \\
$22: 4 \omega 6$ & $1.5 \pm 0.3$ & $0.2 \pm 0.1$ & $0.7 \pm 0.0$ & $0.3 \pm 0.1$ \\
$22: 5 \omega 6$ & $1.5 \pm 0.2$ & $0.4 \pm 0.0$ & $1.2 \pm 0.2$ & $0.6 \pm 0.1^{*}$ \\
$\Sigma \omega 6$ PUFA & $35.3 \pm 0.8$ & $20.5 \pm 1.9^{*}$ & $45.3 \pm 0.8$ & $31.3 \pm 1.5^{*}$ \\
$18: 3 \omega 3$ & $0.1 \pm 0.0$ & $0.1 \pm 0.0$ & $0.4 \pm 0.0$ & $0.4 \pm 0.2$ \\
$20: 5 \omega 3^{\mathrm{b}}$ & $0.2 \pm 0.0$ & $4.0 \pm 0.6^{*}$ & $0.6 \pm 0.0$ & $3.6 \pm 0.5^{*}$ \\
$22: 5 \omega 3$ & $1.7 \pm 0.3$ & $4.9 \pm 0.8^{*}$ & $1.0 \pm 0.2$ & $2.0 \pm 0.2^{*}$ \\
$22: 6 \omega 3^{\mathrm{c}}$ & $6.0 \pm 0.7$ & $15.5 \pm 0.9^{*}$ & $3.9 \pm 0.6$ & $17.2 \pm 1.4^{*}$ \\
$\Sigma \omega 3$ PUFA & $8.1 \pm 0.9$ & $24.7 \pm 1.1^{*}$ & $6.4 \pm 0.8$ & $23.7 \pm 1.3^{*}$ \\
\hline
\end{tabular}

SFA, saturated fatty acids ; MUFA, Monounsaturated fatty acids ; PUFA, Polyunsaturated fatty acids.

${ }^{1}$ Values are means \pm SEM, $n=6$. * indicates significant differences between dietary treatments with $p<0.01$.

${ }^{2}$ Minor fatty acids [14:0, 15:0, 17:0, 19:0, 20:0, 22:0, 24:0, 14:1(n-5), 16:1(n-9), 20:1(n-7), 20:1(n-11), 22:1(n-7), 24:1(n-11), 24:1(n-7), 20:3(n-9), and 22:3(n-9)] are not reported because they represented $<0.3 \%$ of total fatty acids.

Young animals data were previously published in Vinot et al. (2011). Aged animals data were previously published in Languille et al. (2012a).

(brain, retina, liver and adipose tissue) of 6 adult mouse lemurs raised in the breeding colony of Brunoy (UMR CNRS-MNHN 7179). We examined in particular the DHA status in animals raised on the laboratory home-made diet (without any supplementation), especially in the brain cortex and retina, but also in liver, the main organ ensuring the synthesis of DHA from its precursor.

The presence of $\omega 6$-docosapentaenoic acid (22:5 $\omega 6$, DPA), a long-chain end product of the $\omega 6$ series, in the hepatic and plasma phospholipids at a substantial level was indicative of an endogenous synthesis, which could be due to a moderate inadequacy of the amount of $\omega 3$ PUFA in the diet (only traces of $\omega 6$-DPA were present in the diet). The presence of $\alpha$-linolenic acid ( $\alpha$-LNA) in the adipose tissue, the metabolic essential precursor of $\omega 3$ PUFA, is a marker of dietary $\alpha$-LNA intake. Consistently to the presence of $\omega 6$-DPA, the very low content of $\alpha$-LNA in the adipose tissue of the grey mouse lemur ( $0.2 \mathrm{~mol} \%$ of total fatty acids), compared to that found in rat fed an $\alpha$-LNA adequate diet (1\%) (Guesnet et al., 2011) was also indicative of a relative inadequacy in $\omega 3$ in the diet. However, the very low amount of eicosatrienoic acid (20:3 $\omega 9$, ETA), a biomarker of $\omega 6+\omega 3$ PUFA deficiency, indicated that total PUFA intakes are sufficient (Guesnet et al., 2011).

The brain cortex phospholipids were rich in DHA (in brain cortex ethanolamine glycerophospholipid DHA represented $32.0 \mathrm{~mol} \%$ ), although at a lower level than in the retina. It was previously shown in rat submitted to a dose-response effect that the retina and brain phospholipids have their own and specific maximum of DHA incorporation (DHAmax), even though DHA continues to increase in diet (Alessandri et al., 2003). In the rat ethanolamine glycerophospholipid fraction, the DHAmax values were equal to $29 \%$ in the frontal cortex and $46 \%$ in the retina. The values which we found in the mouse lemur, 29 and $47 \%$ respectively, clearly show that the incorporation of DHA into the outer retina is highly similar in the two animal models. It allowed us to conclude that, the mouse lemur raised on the home-made diet efficiently metabolizes the dietary $\omega 3$ PUFA for the optimum modeling of his cortical and retinal membranes. Therefore, the relative inadequacy of $\omega 3$ supplies in the home-made diet seems to be fully compensated by the very efficient transfer of DHA to the neural tissues, excluding on the contrary $\omega 6$-DPA.

\section{$3 \omega 3$ supplementation and cognitive performances in young mouse lemurs}

In the study by Vinot et al. (2011), we investigated the effects of a 5 month long-chain $\omega 3$ PUFA supplementation on behavioral, cognitive and locomotor performances in adult mouse lemurs. Our results evidenced for the first time in a nonhuman primate species that $\omega 3$ PUFA supplementation was able to lower anxiety and spontaneous locomotor activity and concomitantly improved cognitive performances.

Plasma fatty acids from total phospholipids confirmed that animals receiving the fish oil-supplemented diet had significantly higher levels of circulating long chain $\omega 3$ PUFA (including EPA, 22:5 $\omega 3$ and DHA) compared to controls (Tab. 1). The brain fatty acid compositions being not accessible without the sacrifice of animals, plasma fatty acids constituted a proper marker of body fatty acid composition. Indeed, it has been demonstrated in several mammal species that an increase in dietary DHA correlates with plasma DHA content which is in turn predictive of internal organ DHA status and is also a useful biomarker of brain DHA status during adulthood (Kuratko and Salem, 2009). The increased level of $\omega 3$ PUFA in fish oil supplemented animals occurred at the expense of both $\omega 6$ PUFA and monounsaturated fatty acids. These changes contributed to improve the balance between $\omega 3$ and $\omega 6$ PUFA 


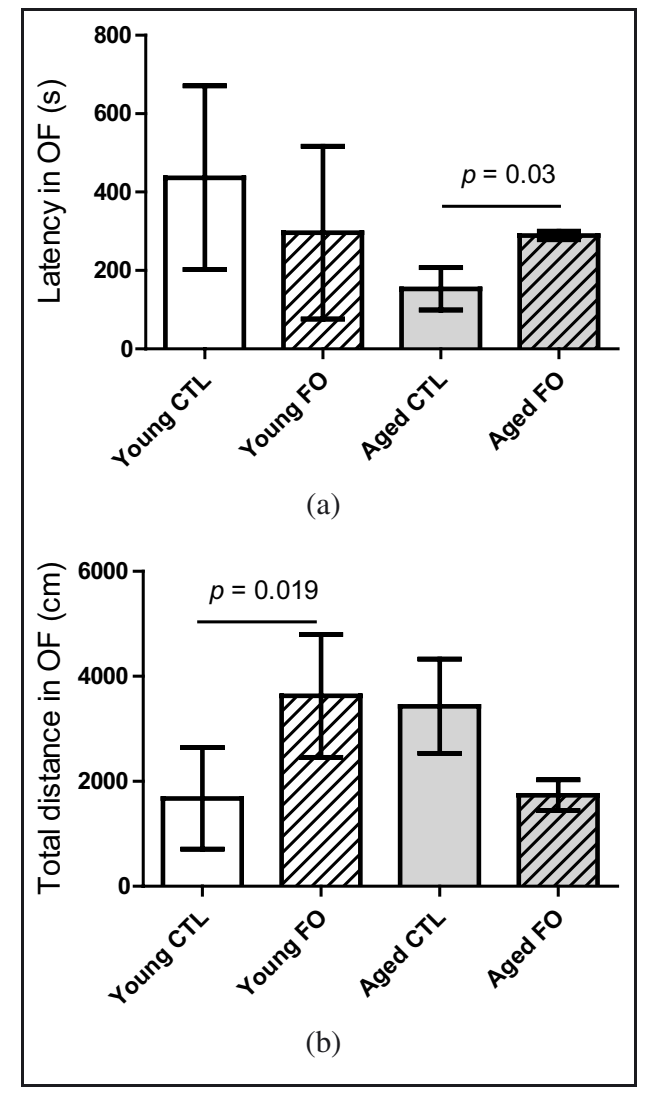

Fig. 2. Performances in an open field (OF) task for young and aged control (CTL) and fish oil (FO) supplemented animals. (a) Latency before first movement (s). (b) Total distance travelled ( $\mathrm{cm}$ ). Values are means \pm SEM, $n=6$ in each dietary and age group. Data of young animals have been previously published in Vinot et al. (2011), Data of aged animals have been previously published in Languille et al. (2012a).

in the plasma phospholipids of fish oil supplemented animals with a ratio of $\omega 6: \omega 3$ of $0.83: 1$ compared to $4.35: 1$ in the control group. It is recommended for human health benefits that the dietary ratio of $\omega 6: \omega 3$ fatty acids should be close to $1: 1$ (Simopoulos, 2009).

$\omega 3$ PUFA-supplemented animals exhibited increased activity during the open field task (increase in traveled distance) (Fig. 2) suggesting a reduction of their anxiety level. As suggested by Prut and Belzung (2003), in this task, anxiolytic treatments (such as $\omega 3$ PUFA in our case) do not increase exploration in the open field but decrease the stress-induced inhibition of exploratory behavior. This observation is corroborated by the lowered spontaneous locomotor activity in a familiar environment measured for $\omega 3$-supplemented animals (not shown, see Vinot et al. 2011 for details). In this test, performed in their breeding room, animals were habituated during $48 \mathrm{~h}$ to their new cage (similar in size and form to their home-cage) previously to the recording of spontaneous locomotor activity during 5 consecutive days. In such conditions, locomotor activity is generally gradually reduced over the testing as the animals are habituated to the cage environment (Fedorova and Salem, 2006). The observation of reduced spontaneous locomotor activity in animals fed the $\omega 3$-supplemented diet corroborates the potential reduced level

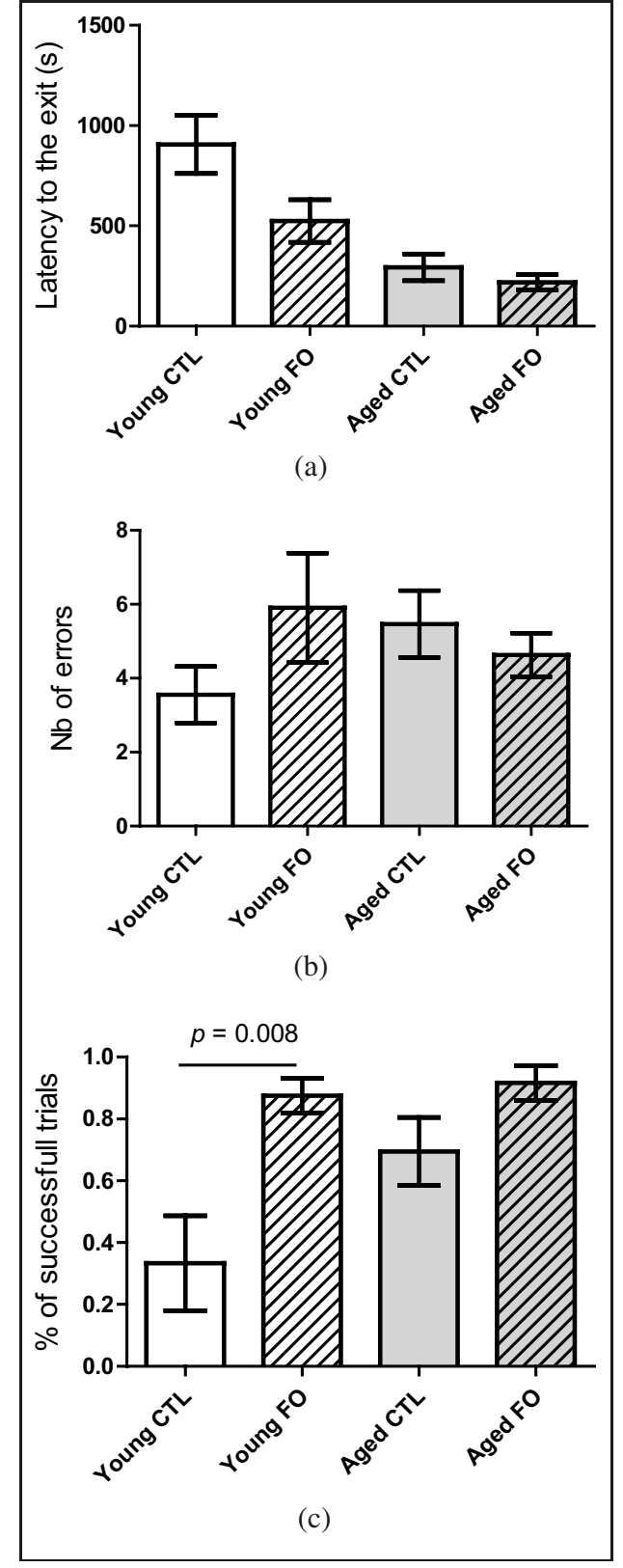

Fig. 3. Performances in the radial arm maze task for young and aged control (CTL) and fish oil (FO) supplemented animals. (a) Latency before reaching the correct exit (s). (b) Number of errors. (c) Rate of success, expressed as the ratio of successful trials on the total number of trials (\%). Values are means $\pm \mathrm{SEM}, n=6$ in each dietary group. Differences were considered significant with $p<0.05$. Data of young animals have been previously published in Vinot et al., 2011. Data of aged animals have been previously published in Languille et al., 2012a.

of anxiety, a parameter that could facilitate the habituation process, a simple form of learning.

In the radial arm maze (Fig. 3), animals of the fish oil group exhibited close to $90 \%$ of success in finding the correct exit compared to $33 \%$ in the control group ( $p=0.0078$ ). Moreover, fish oil supplemented animals tended to spend less time to exit from the maze compared to controls (524 s vs. $906 \mathrm{~s}$; $p=0.060$ ), while their exploratory activity (total number 
of visits, not shown) was increased $(6.8 \pm 1.5$ vs. $3.2 \pm 0.3$; $p=0.061)$. Although these last results did not reach the level of statistical significance, it suggests a tendency to higher exploration for fish oil fed animals. On the other hand, the mean number of errors before finding the correct exit tended to increase in fish oil supplemented animals $(5.9 \pm 1.5)$ compared to controls $(3.6 \pm 0.8)$, but this difference was not significant $(p=0.2)$.

Our finding that fish oil-supplemented mouse lemurs exhibited both lower anxiety in the open field task and better performances in the radial arm maze (\% of success) suggests that the two outcomes may be directly linked. Indeed, the tendency to higher exploration in the radial arm maze of the fish oil supplemented animals (higher number of visits and lower time spent to find the right exit) may be issued from the lowering of anxiety, resulting in a higher score in comparison with more anxious and less exploring animals (trend) of the control group. The difference of performance between the two groups might depend more on their anxiety level than on their intrinsic cognitive capacity, what is corroborated by the absence of a significant difference in the number of errors between control and fish oil groups. Similar findings have been made in rodents which exhibited increased level of anxiety upon chronic $\omega 3$ PUFA dietary deficiency (Carrié et al., 2000; Takeuchi et al., 2003), and decreased anxiety upon DHA supplementation (Takeuchi et al., 2003). Therefore, it is possible that lowering of anxiety underlies better cognitive performances of mouse lemurs raised on the fish oil-enriched diet.

According to Fedorova and Salem (2006), there is some evidence of an enhanced vulnerability to stress of $\omega 3$ fatty acid deficient animals and this factor can influence performance in a variety of tests. Thus, behavioral tasks that involve a higher level of stress may better differentiate behavioral effects related to brain DHA status. They thus emphasize the possible role of non-cognitive factors like emotionality and attention in the impaired performance on different types of learning tasks of $\omega 3$ deficient animals. In any case, if brain DHA status affects performance, this is of importance since performance plays a crucial role in adaptation and therefore survival.

In the study by Vinot et al. (2011), we evidenced that dietary $\omega 3$ fatty acids positively impact on anxiety and concomitantly on cognitive performances in adult mouse lemurs. The observation of decreased anxiety with $\omega 3$ PUFA supplementation is of particular interest in the context of human health. Indeed, even if it exists significant evidence supporting the potential anxiolytic effect of $\omega 3$ PUFA in rodents, there is a lack of studies to demonstrate it, more particularly in primates. The present observations are also very encouraging in the context of aging-associated cognitive decline, in which handling of dietary $\omega 3$ fatty acids could offer an efficient strategy for sustaining cognitive functions. Further studies are in progress in our laboratory to determine whether the effects on cognition and behavior are attributable to the direct improvement of neuronal functions and/or to lowering of anxiety.

The beneficial effect of the fish oil-supplementation in the grey mouse lemur may a priori suggest an improvement of their cerebral DHA status. However, on the basis of the data in animals placed under standard feeding (Pifferi et al., 2012), which have low levels of $\omega 6$-DPA in their brain phospholipids and DHA values close to those of the rat DHAmax, it is likely that the requirements for DHA of the neural tissues are almost fully covered with the standard diet. If this speculation was correct, supplementing the diet of adult animals with fish oil would have resulted in only a modest gain of DHA in the neural tissues. However, in the supplementation study by Vinot (2011) showed that lemurs fed the fish oil-supplemented diet had much higher concentrations of EPA, $\omega 3$-DPA and DHA in their blood plasma phospholipids than those fed the control diet. This allows us to suggest that even a modest gain in brain $\omega 3$ PUFA may have strong beneficial effects on behavior and cognition in non-human primates.

\section{$4 \omega 3$ supplementation and cognitive performances in aged mouse lemurs}

In our study by Languille (2012a), we aimed to determine the effect of dietary fish oil supplementation on exploratory activity, emotional status and spatial memory in aged mouse lemur. Our results revealed that, conversely to young animals, fish oil supplementation decreased the exploratory behavior in a novel environment as revealed by the higher latency to move in open-field (Fig. 2). In addition, and conversely to young lemurs, we observed that fish oil supplementation did not significantly improve the spatial memory performance in radial arm maze task (Fig. 3).

During the open-field task the latency of first movement was significantly higher in fish oil supplemented animals compared to controls and they exhibited a tendency to travel less (indicative of increase anxiety related behavior). This observation suggests that the impact of $\omega 3$ fatty acids supplementation highly differs according to age. Very few studies have investigated the impact of $\omega 3$ fatty acids supplementation on such behaviors in old animals. Carrié et al. (2000) showed that fish oil supplementation starting in the perinatal period tends to decrease the exploratory activity in the 5-min open-field test, and significantly decreased locomotor activity in a 20-min cage test, in 17-19-months-old mice. Conversely, in 1 month old mice, the level of locomotor activity was significantly higher in fish-oil-fed animals than in the control group. This study suggests that fish oil diet affects behavior differently across aging: increasing locomotor activity in adult and decreasing it in old mice.

During the radial arm maze task we observed that fish oil supplementation inclined to increase the ability to find the correct exit (\% of success, not significant, Fig. 3). This observation is in agreement with the two clinical trials in cognitively healthy elderly subjects (aged 65 years or older) in which the authors showed no positive effect of $\omega 3$ fatty acids supplementation during 6.5 months (van de Rest et al., 2008) and 24 months (Dangour et al., 2010) on any cognitive aspects (attention, memory, executive function). In the study using young adult mouse lemurs (Vinot et al., 2011) we reported that fish oil supplementation did not modify the latency to reach the target and the number of errors in the radial arm maze task, but significantly improved the \% of successful trials. Taken together, these observations indicate that fish oil supplementation in both adult and aged mouse lemur had no 
effect on memory performance in a little stressful task but improved (or tended to improve in aged animals) the rate of success, what can be a sign of lower anxiety or higher arousal and/or motivation.

To our knowledge, only two studies have shown a positive effect of $\omega 3$ fatty acids on cognitive functions in aged animals. Supplementation of DHA during 7 weeks reduced the number of errors in a passageway water maze test in 15 months old mice (Jiang et al., 2009). Gamoh et al. (2001) showed that 25 months old rats supplemented with DHA during 5 weeks expressed less reference and working memory errors in radial arm maze. However, the improvement was only observed in the latter phase of learning, after more than 21 days of training with two daily trials. These studies suggested that $\omega 3$ fatty acids dietary supplementation is able to limit the apparition of cognitive deficit, even when the administration starts at old age. Conversely, some studies using fish oil supplementation did not reveal improvement of spatial learning or memory in the Morris water maze test in aged rodents (Barceló-Coblijn et al., 2003; Calon et al., 2003; Sergeant et al., 2011). Finally, it is noteworthy that in the study with aged monkeys supplemented with DHA (Tsukada et al., 2000), only 4 weeks of treatment led to increased regional cerebral blood flow, a parameter closely linked to neuronal activation. Our findings in lemurs seem to indicate that $\omega 3$ PUFA supplementation is not efficient to counteract the age-related declines in old non-human primate when started at old age.

On the basis of fatty acid composition of brain and retinal tissues (Pifferi et al., 2012), it is likely that the requirements for DHA of the neural tissues are almost fully covered with the control diet. Plasma fatty acids determination in aged animals showed that the fish oil supplemented lemurs exhibited significantly higher levels of plasma long chain $\omega 3$ PUFA (including EPA, 22:5 $\omega 3$ and DHA) compared to controls (Tab. 1). The increased level of $\omega 3$ PUFA in fish oil supplemented animals occurred at the expense of both $\omega 6$ PUFA and monounsaturated fatty acids. These changes contributed to improve the balance between $\omega 3$ and $\omega 6$ PUFA in the plasma of fish oil supplemented animals with a ratio of $\omega 6: \omega 3$ of $1.3: 1$ compared to $7: 1$ in the control group. Since these observations were highly comparable to those made in young animals, it allows us to suggest that brain incorporation of $\omega 3$ PUFA may be less efficient in aged animals compared to young. This is consistent with observations made in aged animals in which it was reported a significant decrease in the level and turnover of PUFA during aging in rodents (reviewed by Yehuda et al., 2002). In humans no such differences have been evidenced, even if differences in plasma incorporation of long-chain $\omega 3$ PUFA between young and aged subjects has been recently described (Fortier et al., 2010), with higher levels for aged healthy subjects. This apparent paradox, that still remains to be fully explained, is indicative of a difference in fatty acids metabolism between young and aged subjects, as revealed by Walker (2013).

\section{Conclusions}

Structural and functional modifications of the brain during aging could explain that fatty acids act differently on behavior in function of age. Aged animal may differ from young due to age-related changes in $\omega 3$ fatty acid metabolism. One beneficial role of $\omega 3$ fatty acids in young animals could be driven by enhancement of neurogenesis since this process seems to be age-dependent (Lazic et al., 2012). Neurogenesis, previously thought to occur only in the embryo, is now known to take place in the adult brain, dependent on numerous stimulating and inhibiting factors, including dietary components. Because of classic associations between neurogenesis and the hippocampus, in learning and cognition, this brain region has also been the focus of attention when studying the links between diet and neurogenesis (Yon et al., 2013). The hippocampus represents one of the two areas in the mammalian brain in which adult neurogenesis occur. This process is associated with beneficial effects on cognition. The exposure to $\omega 3$ fatty acids enhances adult hippocampal neurogenesis associated with cognitive and behavioral processes, promotes synaptic plasticity and modulates synaptic protein expression, thereby stimulating the dendritic arborization and new spine formation (Crupi et al., 2013). The grey mouse lemur breeding colony of Brunoy (UMR CNRS-MNHN 7179) is in the unique situation to test if the behavioral cognitive improvements observed after $\omega 3$ fatty acids supplementation are indeed linked to an enhancement of neurogenesis in a well-established primate model. We hope such studies will help to improve our understanding of the mechanisms of age related impairments in cognitive function that challenge our society in many ways.

Acknowledgements. The author thanks the support of Philippe Guesnet and Fabienne Aujard in the achievement of the studies of $\omega 3$ fatty acids in the Grey mouse lemur. This work was financially supported by the Groupe Lipides et Nutrition (part of the Association Française pour l'Étude des Corps Gras), the Centre National de la Recherche Scientifique/Muséum National d'Histoire Naturelle, and the Institut National de la Recherche Agronomique.

\section{References}

Alessandri JM, Poumès-Ballihaut C, Langelier B, et al. 2003. Incorporation of docosahexaenoic acid into nerve membrane phospholipids: bridging the gap between animals and cultured cells. Am. J. Clin. Nutr. 78: 702-710.

Barberger-Gateau P, Samieri C, Féart C, Cunnane S. 2013. Acides gras oméga-3 et déclin cognitif : la controverse. OCL 20: 88-92.

Barceló-Coblijn G, Högyes E, Kitajka K, et al. 2003. Modification by docosahexaenoic acid of age-induced alterations in gene expression and molecular composition of rat brain phospholipids. Proc. Natl. Acad. Sci. USA 100: 11321-11326.

Bégin ME, Plourde M, Pifferi F, Cunnane SC. 2010. Are fish and docosahexaenoic acid linked to lower risk of cognitive decline and Alzheimer's disease? In: Ramassamy C, Bastianetto S, eds. Recent advances on nutrition and the prevention of Alzheimer's disease. Kerala (India) Transworld Research Network, 2010.

Bégin ME, Plourde M, Pifferi F, Cunnane SC. 2010. What is the link between docosahexaenoic acid, cognitive impairment, and Alzheimer's disease in the elderly? In: Montmayeur JP, le Coutre J, eds. Fat detection: taste, texture, and post ingestive effects. Boca Raton (FL): CRC Press, 2010.

Calon F, Lim GP, Yang F, et al. 2004. Docosahexaenoic acid protects from dendritic pathology in an Alzheimer's disease mouse model. Neuron 43: 633-645. 
Carrie, Clement M, De Javel D, Frances H, Bourre JM. 2000. Phospholipid supplementation reverses behavioral and biochemical alterations induced by $\omega 3$ polyunsaturated fatty acid deficiency in mice. J. Lipid. Res. 41: 473-480.

Carrié I, Guesnet P, Bourre JM, Francès H. 2000. Diets containing long-chain $\omega 3$ polyunsaturated fatty acids affect behaviour differently during development than ageing in mice. $\mathrm{Br}$ J. Nutr. 83: 439-447.

Chalon S, Delion-Vancassel S, Belzung C, et al. 1998. Dietary fish oil affects monoaminergic neurotransmission and behavior in rats. $J$. Nutr. 128: 2512-2519.

Crupi R, Marino A, Cuzzocrea S. 2013. $\omega 3$ fatty acids: role in neurogenesis and neuroplasticity. Curr. Med. Chem. 20: 2953-2963.

Dal-Pan A, Pifferi F, Marchal J, Picq JL, Aujard F. 2011. RESTRIKAL Consortium. Cognitive performances are selectively enhanced during chronic caloric restriction or resveratrol supplementation in a primate. PLoS One 6: e16581.

Dangour AD, Allen E, Elbourne D, et al. 2010. Effect of 2-y $\omega 3$ longchain polyunsaturated fatty acid supplementation on cognitive function in older people: a randomized, double-blind, controlled trial. Am. J. Clin. Nutr. 91: 1725-1732.

Fedorova I, Salem N Jr. 2006. Omega-3 fatty acids and rodent behavior. Prostaglandins Leukot. Essent. Fatty Acids 75: 271-289.

Fortier M, Tremblay-Mercier J, Plourde M, et al. 2010. Higher plasma $\omega 3$ fatty acid status in the moderately healthy elderly in southern Québec: higher fish intake or aging-related change in $\omega 3$ fatty acid metabolism? Prostaglandins Leukot. Essent. Fatty Acids 82: 277-280.

Gamoh S, Hashimoto M, Hossain S, Masumura S. 2001. Chronic administration of docosahexaenoic acid improves the performance of radial arm maze task in aged rats. Clin. Exp. Pharmacol. Physiol. 28: 266-270.

Guesnet P, Alessandri JM, Astorg P, Pifferi F, Lavialle M. 2005. Les rôles physiologiques majeurs exercés par les acides gras polyinsaturés (AGPI). OCL 12: 333-343

Guesnet P, Lallemand SM, Alessandri JM, Jouin M, Cunnane SC. 2011. Alpha-Linolenate reduces the dietary requirement for linoleate in the growing rat. Prostaglandins Leukot. Essent. Fatty Acids 85: 353-360.

Jiang LH, Shi Y, Wang LS, Yang ZR. 2009. The influence of orally administered docosahexaenoic acid on cognitive ability in aged mice. J. Nutr. Biochem. 20: 735-741.

Kuratko CN, Salem N Jr. 2009. Biomarkers of DHA status. Prostaglandins Leukot. Essent. Fatty Acids 81: 111-118.

Languille S, Aujard F, Pifferi F. 2012. Effect of dietary fish oil supplementation on the exploratory activity, emotional status and spatial memory of the aged mouse lemur, a non-human primate. Behav. Brain Res. 235: 280-286.

Languille S, Blanc S, Blin O, et al. 2012. The grey mouse lemur: a non-human primate model for ageing studies. Ageing Res. Rev. 11: $150-162$.

Larrieu T, Madore C, Joffre C, Layé S. 2012. Nutritional $\omega 3$ polyunsaturated fatty acids deficiency alters cannabinoid receptor signaling pathway in the brain and associated anxiety-like behavior in mice. J. Physiol. Biochem. 68: 671-681.

Lavery WL. 2000. How relevant are animal models to human ageing? J. R. Soc. Med. 93: 296-298.
Lavialle M, Champeil-Potokar G, Denis I, Guesnet P, Pifferi F, Vancassel S. 2007. Le DHA dans la neurotransmission. OCL 14: $11-15$

Lazic SE. 2012. Modeling hippocampal neurogenesis across the lifespan in seven species. Neurobiol. Aging 33 1664-1671.

Mathieu G, Oualian C, Denis I, Lavialle M, Gisquet-Verrier P, Vancassel S. 2011. Dietary $\omega 3$ polyunsaturated fatty acid deprivation together with early maternal separation increases anxiety and vulnerability to stress in adult rats. Prostaglandins Leukot. Essent. Fatty Acids 85: 129-136.

Perret M, Aujard F. 2001. Daily hypothermia and torpor in a tropical primate: synchronization by $24-\mathrm{h}$ light-dark cycle. Am. J. Physiol. Regul. Integr. Comp. Physiol. 281: R1925-1933.

Picq JL. 2007. Aging affects executive functions and memory in mouse lemur primates. Exp Gerontol. 42: 223-232.

Picq JL, Aujard F, Volk A, Dhenain M. 2012. Age-related cerebral atrophy in nonhuman primates predicts cognitive impairments. Neurobiol. Aging 33: 1096-1109

Pifferi F, Perret M, Guesnet P, Aujard F, Alessandri JM. 2012. Fatty acid composition of the brain, retina, liver and adipose tissue of the grey mouse lemur (Microcebus murinus, primate). Lipids 47: 793-801.

Prut L, Belzung C. 2003. The open field as a paradigm to measure the effects of drugs on anxiety-like behaviors: a review. Eur. J. Pharmacol. 463: 3-33.

Ross BM. 2009. Omega-3 polyunsaturated fatty acids and anxiety disorders. Prostaglandins Leukot. Essent. Fatty Acids 81: 309-312.

Sergeant S, McQuail JA, Riddle DR, et al. 2011. Dietary fish oil modestly attenuates the effect of age on diastolic function but has no effect on memory or brain inflammation in aged rats. J. Gerontol. A Biol. Sci. Med. Sci. 66: 521-533.

Simopoulos AP. 2009. Evolutionary aspects of the dietary omega6:omega-3 fatty acid ratio: medical implications. World Rev. Nutr. Diet. 100: 1-21.

Takeuchi T, Iwanaga M, Harada E. 2003. Possible regulatory mechanism of DHA-induced anti-stress reaction in rats. Brain Res. 964: 136-143.

Tsukada H, Kakiuchi T, Fukumoto D, Nishiyama S, Koga K. 2000. Docosahexaenoic acid (DHA) improves the age-related impairment of the coupling mechanism between neuronal activation and functional cerebral blood flow response: a PET study in conscious monkeys. Brain Res. 862: 180-186.

van de Rest O, Geleijnse JM, Kok FJ, et al. 2008. Effect of fish oil on cognitive performance in older subjects: a randomized, controlled trial. Neurology 71: 430-438.

Vinot N, Jouin M, Lhomme-Duchadeuil A, et al. 2011. Omega-3 fatty acids from fish oil lower anxiety, improve cognitive functions and reduce spontaneous locomotor activity in a non-human primate. PLoS One 6: e20491.

Walker CG, Browning LM, Mander AP, et al. 2013. Age and sex differences in the incorporation of EPA and DHA into plasma fractions, cells and adipose tissue in humans. Br J. Nutr. 24: 1-11.

Yehuda S, Rabinovitz S, Carasso RL, Mostofsky DI. 2002. The role of polyunsaturated fatty acids in restoring the aging neuronal membrane. Neurobiol. Aging 23: 843-853.

Yon MA, Mauger SL, Pickavance LC. 2013. Relationships between dietary macronutrients and adult neurogenesis in the regulation of energy metabolism. Br J. Nutr. 109: 1573-1589.

Cite this article as: Fabien Pifferi. Omega-3 PUFA supplementation differentially affects behavior and cognition in the young and aged non-human primate Grey mouse lemur (Microcebus murinus). OCL 2014, 21(1) A104. 